\title{
Utilization of Family Planning and Volunteer Counseling and Testing Service and Associated Factors among Preparatory School Students in Arba Minch Town, Southern Ethiopia: A Cross- Sectional Study
}

\section{Melaku Mata}

Arba Minch University

Gizaw Sisay ( $\nabla$ gizsisay@gmail.com )

Dilla University

Meseret Girma

Arba Minch University

Zeleke Girma

Arba Minch University

Fitsum Wolde

Arba Minch University

Getasew Berhanu

Dilla University

\section{Research Article}

Keywords: Adolescent, Family Planning, voluntary counseling and testing, reproductive health, Southern Ethiopia

Posted Date: July 12th, 2022

DOI: https://doi.org/10.21203/rs.3.rs-717317/v3

License: (c) (i) This work is licensed under a Creative Commons Attribution 4.0 International License.

Read Full License 


\section{Abstract}

Background: The utilization of reproductive health service plays significant role in preventing youths from different reproductive related health problems. Adolescents in Ethiopia have inadequate access to information and services.

Objective: To assess utilization of family planning and volunteer counseling and testing service and associated factors among preparatory school students in Arba Minch Town.

Method: Institutional based cross sectional study was conducted among randomly selected 522 regular preparatory students in Arba Minch Town from December 01-30/2019. Data was entered and clean into Epidata-4.6 templates then transferred to SPSS-25 statistical software for analysis. A bi-variable and multivariable logistic regression model was used to identify statistically significant variables of the independent variable. Variables with P-value $<0.05$ in the final model were considered significant determinant variables.

Result: Out of those who had sexual intercourse $78.6 \%$ and $29.3 \%$ of them used family planning and voluntary counseling and testing service, respectively. Sexual intercourse experienced adolescents were 8.24 times more likely utilized $\mathrm{F} / \mathrm{P}$ service than their counterparts ( $\mathrm{AOR}=8.236,95 \% \mathrm{Cl}: 6.18-15.76)$. The study participants living with both parents were about 1.6 times ( $A O R=1.645, \mathrm{Cl}: 1.077-2.513$ more likely to use voluntary counseling and testing service compared to those who living with others.

Conclusions and Recommendations: Based on this finding majority (more than three fourth) of adolescents used family planning, but voluntary counseling and testing service utilization were low. The reasons for not utilizing family planning and voluntary counseling and testing service were felt ashamed from friends and unfriendly approach of health workers during service provision. So, we can recommend that encourage adolescents open discussion about reproductive health service utilization with different peoples, open discussion within couples and encourage to increase female education are important steps to improve adolescent's reproductive service utilization.

\section{Background}

Reproductive health $(\mathrm{RH})$ is defined as "A state of physical, emotional, and social well-being, not merely the absence of illness or infirmity, in all matters relating to the reproductive system and its functions and processes. It includes human sexual activity and reproductive processes and implies that people can have a "responsible, satisfying, and safe sex life, as well as the ability to reproduce and the freedom to choose whether, when and how often they reproduce ${ }^{2}(1)$. Reproductive health is universal concern, but it is special importance for female during reproductive period. However male also demands specific reproductive health needs and have power in some reproductive health matters (2).

Adolescence is can be described as those youths age found between 10 up to 19 years (3). It is transition period from youthful to maturity (4). It is demarcated by significant change in physical, mental, emotional 
and behavior. Adolescence is the time of assignation of an extensive variety of activities that put their life at high risk (5). And it can also characterized as a period of high risk taking because adolescents are susceptible to behavioral problems $(6,7)$. Among these behavioral problem during puberty are; physical health problem consequences such as abortion, school dropout, out of marriage vows as well as pushing prone to sexually transmitted diseases such as HIV (8). All these problems can be prevented through sexual and reproductive health service uptake (3). The benefits of practicing family planning method is encompassing economic growth, prevents pregnancy-related health risks for women, particularly for adolescent girl, educational advances, and women's empowerment (9). Contraceptive use has multiple benefits. It prevents unplanned pregnancies, decreases the number of abortion, and reduces the incidence of death and disability interrelated to complication pregnancy, and childbirths. The benefits of it for longrange of time is increased education for women, and better family health to better family income and robust national economic growth. Increased contraceptive use and reduced unmet need for contraception are essential to improve maternal and adolescent health, and combating HIV (10).

The decisions made during this period of life affect not only the individual welfare of adolescences, but also the wellbeing of whole people. The proportion of unmet need among married \& unmarried female adolescence in Central and West Africa is $29.3 \& 41.7 \%$, respectively. In general, married adolescents aged 15-19 experience greater unmet need than all married women. Generally, the rate of family planning practice is low in all regions in SSA among 15-19-year old married female adolescent. In Ethiopia there are various cultural and social barriers for gender equality, resulting in poor reproductive indices and high prevalence of harmful traditional practices (11).

Ethiopia is a country which unsafe abortion is a prominent cause of maternal mortality and injury (15). However as many research findings disclosure that the RHS utilization among adolescents are lower than other age categories (18).

Adolescents in Ethiopia have limited access to SRH information (19). Despite of the high rate of SRH problems; the access of acceptable SRH services to adolescents is very low (20-22). This poses a major public health problem such as maternal deaths and other complications resulting from early marriage, unplanned pregnancy, and unsafe abortion in the country. From the overall burden of disease due to complicated child birth; Adolescent women accounts for $23 \%$ of among women of all ages $(23,24)$.

Worldwide the estimated number of 3.2 million unsafe abortions occur each year among youth girls aged 15-19 years (17). According to the 2016 Ethiopian Demographic and Health Survey report, among sexually active adolescents aged $15-19$ years, adults who were tested for HIV test were only $22 \%$ and $18 \%$ respectively (15). Adolescents' RHS uptake is low particularly in the Southern Ethiopia in which study area is found (23).

Therefore it is important to further investigate what other factors affect the utilization and what are these factors in the context of Arba Minch and to gain a better understanding of the reasons for low utilization of the service as a first step towards the reduction of teenage pregnancy, unsafe abortion and other reproductive health problems. 
The objective of this study was to assess reproductive health services utilization of adolescents in preparatory schools in Arba Minch Ethiopia. Determining the prevalence of reproductive health service utilization in Arba Minch will contribute to pave the identified gaps and solve the problems related to the service utilization.

\section{Methods}

Study Design and Period: School based cross-sectional study was conducted to assess utilization of family planning and volunteer counseling and testing service and associated factors among preparatory school students in December 2019.

Study Area: The study was conducted in Arba Minch town which is found in Gamo zone, the Southern Nations Nationalities and Peoples Region (SNNPR). It is located in Southern $505 \mathrm{~km}$ far from Addis Ababa (capital city of Ethiopia) and $275 \mathrm{~km}$ southwest of Hawassa (capital town of the regional state). It is structured or divided in to 4 sub city and 11 kebeles in order to facilitate socio-economic development of the town residents. Arba Minch is home to14 governmental health facilities, 34 private clinics, 13 drug store and 2 community pharmacy providing health care services for the community and also 23 primary schools [ 8 Governmental, and 15 private ( 4 of them are 1-4 grade)], 9 high schools ( 5 Governmental and 4 privates) and 6 preparatory schools ( 3 Governmental and 3 private schools). All students in randomly selected preparatory schools in Arba Minch town were the study population.

All regular students between age of 15-19 years old enrolled in to preparatory school in 2019 and regular preparatory school students drop out from school, and severely sick during the data collection period were exclude.

\section{Sample Size Determination}

A single population proportion formula was used to calculate the required sample size by assuming estimated proportion of RH among preparatory adolescents $(p)=67.3 \%$ in Goba town (28), confidence level of $95 \%$, and $5 \%$ of margin of error. Because of multistage sampling method was used; sample size was multiplied by design effect 1.5 and the final sample sizes became 541 . Sample size was calculated for second outcome variable; but lower than the sample size calculated from the first outcome variable and we took the larger one.

\section{Sampling Technique}

After calculating sample size, two stage sampling technique was used to select the study participant. Firstly, students were stratified in to eleventh and twelve's grade stream. The sample size was distributed to each grade proportional to their size. The samples were selected by using simple random sampling (SRS) technique from each grade. Generally, the required numbers of students were selected by computer generated numbers from each grades and sex (Figure 1). 
Data was collected using semi-structured and pre-tested questionnaire by self-administered method. The questionnaire was adopted by reviewing different literature $(20,28)$ and some of the variables were adopted from the EDHS questionnaire. Data collection period was from Dec. 10-13/2019. School instructors were used as a data collection facilitator. The purpose of the study was explained to study participants in order to identify the clarity of questionnaires and their sensitiveness.

To assure the quality of the data, training was given for data collectors and supervisors. The questionnaires was prepared originally in English and translated to Amharic then back to English. Pretesting of the questionnaire was performed on $5 \%$ of the sample in similar setting students in Birbir preparatory which is found near to Arba Minch town) before the actual data collection to ensure its clarity, ordering, and consistency. Based on the input from the pretest some questions were rewritten, and the final questionnaire was prepared. The trained school instructors were facilitate the data collection process and check the completeness of the questionnaires. To assure privacy of the information, each participant was assigned to a single sparsely placed seat. Each questionnaire was checked for completeness of the information jointly by the supervisors, and incomplete and inconsistency filled questionnaires were returned to the respondents so that they fill it in full at the data collection site.

\section{Operational Definitions of the Study Variables}

Reproductive health services: particularly considered in this study are FP and VCT services.

FP service utilization: Is defined as ever use of any modern contraceptives in the last one year.

VCT service utilization: It is measured by requesting study participants getting HIV testing service voluntary in the last 12 months (20).

\section{Data Management and Analysis}

Data was entered in to Epi-Data version 4.6 and export to SPSS Version 25 software package for analysis. Descriptive statistics of variables were performed by frequency distribution tables and figures. Bivariable logistic regression was used to identify the association between the dependent and independent variable. The variables whose significance level less than $\mathrm{P}<0.25$ were considered as candidate for the multivariable logistic regression analysis. Before multivariable analysis, independent variables were checked for multi-colinearity effect using correlation matrix. Hosmer-Lemshow test was used to test goodness-of-fit to assess whether the necessary assumptions for application of multivariable logistic regression. Finally to determine the independent factors associated with F/P and VCT utilization, multivariable logistic regression was done. The strength of association was interpreted using the adjusted odds ratio and $95 \% \mathrm{Cl}$. Variables with P-value $<0.05$ in the final model was considered statistically significant.

\section{Results}




\section{Socio Demographic Characteristic of the Study Participants}

From the total of 541 students, 522 responded to the questionnaires yielding a response rate of $96.48 \%$. Majority of the students $296(56.7 \%)$ were males. The mean age of the study participant was 17.8 with $(S D \pm 0.8)$ years. Among the respondents, $216(41.4 \%)$ and $306(58.6 \%)$ were attending grade $11^{\text {th }}$ and grade $12^{\text {th }}$ respectively. Two hundred fifty two (48.3\%) respondents were Orthodox religion follower followed by protestant 247(47.3\%) and Muslim 22(4.2\%). Gamo 380(72.8\%) and Gofa 44(8.4\%) constitute the major ethnic group. The majority of the respondents $499(95.6 \%)$ were unmarried. Regarding to participants family educational status $160(30.7 \%)$ of fathers and $72(13.8 \%)$ of mothers were above secondary education (Table 1 ).

\section{Sexual History of the Participants}

Out of 522 participants $307(58.8 \%)$ have boy/girlfriend and among these $141(45.9 \%)$ of them had two and above two sexual partners. From a total participants 159(30.5\%) have had sexual intercourse with their friends in the past 12 months (Table 2).

\section{Awareness and Source of Information}

About $468(89.7 \%)$ of study participants were heard information about reproductive health services, among these $324(62.1 \%)$ and $297(56.9 \%)$ of the participants had information (awareness) about family planning and VCT services respectively. The most common source of information for respondents were mass media and health care provider followed by teachers. 316(60.5\%) study participants were discussed about reproductive health service, 174(33.3\%) and 195(37.4\%) of the study subjects were discussed about family planning and VCT services respectively. One hundred ninety seven (37.7\%) were discussed with their friends or peer groups followed by parents or guardian $94(18 \%)$ (Table 3$)$.

\section{Family Planning Service Utilization}

Among sexual intercourse experienced study participants 125(78.6\%) utilized FP service. Male condoms were most commonly used $79(63.2 \%)$ followed by $45(36 \%)$ pills and the least used modern contraceptive was female condom only four (3.2\%) during their sexual intercourse. The major reason for not using family planning service for $162(31 \%)$ of the study participant was have no money for the service followed by one hundred thirty six (26.1) felt ashamed from their friends (Table 4).

Voluntary Counseling and Testing Service Utilization

Among 522 students participated in this study, 153(29.3\%) of them had voluntary counseling and testing service. The reason for not using VCT service were felt ashamed from friends 171 (32.8\%) followed by eighty six (16.5\%) of non-convenient behavior of health care providers (Table 5). 
In the bi-variable logistic regression analysis at $\mathrm{p} \otimes 0.25$ in $95 \% \mathrm{Cl}$ factors such as sex, marital status, coresidence, mother's educational level, father occupation, discussing about $\mathrm{RH}$ and $\mathrm{F} / \mathrm{P}$, discussing on $\mathrm{RH}$ with parents and health care providers and having sexual intercourse experience were associated with family planning service utilization. But in multivariable analysis at p-value $₫ 0.25$ at the level of $95 \% \mathrm{Cl}$, marital status, ever had boy or girl friend ever had sexual intercourse with in the past 12 months and discussing on $\mathrm{RH}$ with parents were found to be significantly associated with family planning service utilization. Based on this study the odds of family planning service utilization among adolescents those experienced sexual intercourse were 8.24 times $(A O R=8.24,95 \% \mathrm{Cl}: 6.1-15.76)$ more likely to utilize F/P service than abstainers. Adolescents who had discussion on $\mathrm{RH}$ with their parents were about 2.766 times (AOR= 2.766, Cl: 1.25-6.12) more likely to use the service those who do not have discussion with their parents (Table 6).

\section{Associated factors for Voluntary Counseling and Testing Service Utilization}

Based on bivariable analysis at $\mathrm{p} \otimes 0.25$ factors such as co-residence, mother educational status, discussing about $\mathrm{VCT}$, discussing on $\mathrm{RH}$, discussing on $\mathrm{RH}$ with friends and health care providers were found to be associated with VCT service utilization.

Out of the variables which entered to multivariable logistic regression model, at $\mathrm{p} \otimes 0.05$ factors such as co-residence with both parents, mother educational status, discussing about VCT and discussing on RH with health care providers were statistical significant determinants of VCT service use. The study participants living with their both parents were about 1.63 times (AOR=1.631, Cl: 1.07-2.49) more likely to use VCT service compared to those who living with others or alone. The children of formal educated mothers were about 1.88 times more likely to utilize VCT service than those whose mothers had no formal education (AOR=1.888, $\mathrm{Cl}$ : 1.06-3.36). In this study adolescents who discussing about VCT service and discussing about Rh with health care providers were about 2.077 and 2.53 times more likely to utilize VCT service when compared to their counterparts (AOR=2.077, Cl: 1.207-3.573 and AOR=2.532, Cl: 1.1434.609) respectively (Table 7).

\section{Discussion}

One of the most important aspects of the health extension program is the adolescent reproductive health which is designed to focus on the production of healthy adolescents that will effectively succeed the present generation (1). This school-based study assessed the patterns of family planning and VCT service utilization and associated factors is important to evaluate the progress towards addressing reproductive health problems of adolescents. VCT is an essential element of RH service in the fight against HIV/AIDS. Family planning service utilization is critical in preventing adolescents from different 
health and health related problems that have a negative impact on the overall aspects of adolescents' health status. In this study, the overall utilization of family planning service among sexual intercourse experienced adolescents was $78.6 \%$. This finding was nearly in agreement with the studies conducted in Nigeria $81.6 \%$, Gondar $79 \%$ and Goba $72.4 \%(20,23,28)$. However, this finding was higher than the study conducted in Hadyia zone $64.5 \%$, North Shewa $27.9 \%$ and Kachabirra $17.6 \%(25,31,35)$. This difference might be due to different characteristics of individuals between the study areas and design, whereas this study was conducted in urban and have higher educational level; so adolescents might have good knowledge and attitude towards family planning service utilization.

This study revealed that VCT service utilization was $29.3 \%$ from total study participant and $31.6 \%$ from sexually active study subjects. This study outcome is similar with the finding of the study conducted in Kachabira 38.2\% Southern Ethiopia (25). And also, lower than the research findings done in Nekemt $59.2 \%$, Ancha $45.8 \%$ and Karamoja region, Uganda $82 \%(24,32,35)$. This variation could be due to the recent nationwide noticeable emphasis decrement no the fight against HIV/AIDS related health promotion and preventive activities. Other reason could be as the study finding feeling ashamed from friends and unfriendly handling and non-convenient behavior of health care providers.

This study revealed married adolescents were 4.24 times more likely utilized F/P service than their counterparts. This could be due to increased open discussion on sexual and reproductive health issues or family planning between couples. This finding is consistent with a study done in Kenya and Harar, Ethiopia $(21,36)$.

In this study discussing on $\mathrm{RH}$ with parents were found to be significantly associated with family planning use than their counterparts. Discussion on the service with different people has an effect on F/P service utilization. Adolescents who discussed about RH service with their parents were utilized family planning more than those who do not discussed. This is consistent with the studies conducted in Gondar and Anchar $(20,32)$. This variation might be because of discussion allows adolescents to create opportunity exchange information that increases further understanding about $\mathrm{RH}$ service and its benefit.

The practice of family planning service utilization among adolescences who have had sexual intercourse in last one year was higher than abstainers. This finding is consistent with the study done in Goba and Nekemet $(24,28)$. The possible reason sexually experienced individuals might have more time to discuss with their partner about family planning to avoid the risk and consequences of sexual vulnerability and they may also care each other.

VCT service utilization among adolescents co-residence with both parents were high when compared with those who live others or alone. This is similar with the study conducted in East Gojjam (27). This difference could be because of information and experience exchange among parents. In this study maternal educational status affects VCT service utilization. In this study adolescents of formal educated mothers were utilize VCT service more than that of the children of illiterate mothers. This finding supported by the study conducted in Goba (28). The possible justification could be educated mothers may have better information and awareness about HIV/AIDS and VCT they may encourage their children 
to utilize the service. In this study adolescents who discussion on VCT service with health care providers utilize more than not discussed with health care providers. This is also observed in the study conducted in Medawolabu University, Gondar and Goba $(20,28)$. This could be justified as discussion about VCT with health care providers allows adolescents to exchange better information that facilitate further understanding and avoid misunderstanding on the service. Also discussing with health worker may not need referral to other health professional for the service.

\section{Strength and Limitation}

This study addressed previously unscathed and currently which is area of public health concern. Gender balance is considered during sampling technique by proportionally allocating for both sexes each grade. Data was collected through self-administered questionnaire which may decrease social desirability bias.

\section{Limitation}

This study share the limitations of cross sectional studies. It is impossible to decide causal relationship among dependent and independent variables. This study was conducted in two randomly selected governmental preparatory schools, which means the result, may not generalize to adolescents from private preparatory schools and for rural adolescents.

\section{Conclusions}

In general majority of sexual intercourse experienced adolescents were used family planning service whereas VCT service utilization was low. This study shows that marital status, Discussed on with parents, having boy or girlfriend and ever had sexual intercourse were the factors affecting F/P service utilization, whereas co-residence both parents, mother educational status, discussed with Health care providers and discussed about VCT were the significantly determinant factors for VCT service utilization. The reason for not utilizing F/P service was having no money for the service followed by felt ashamed from friends, but felt ashamed from friends followed by harsh and unfriendly approach of health care providers during service provision were the two major reasons for not utilizing VCT service.

Based on the study finding, we can recommend that to health initiation and health care providers:

Encourage adolescents open discussion about RHS utilization, couples open discussion about RHS utilization, Encourage couples open discussion about RHS utilization and encourage female education.

\section{Abbreviations}

AIDS, Acquired Immune Deficiency Syndrome; AOR, Adjusted Odds Ratio; ARH, Adolescent Reproductive Health; DHS, Demographic and Health Survey; FGC, Female Genital Cutting; HIV, Human Immune Deficiency Virus; IEC, Information, Education and Communication; RH, Reproductive Health; SRH, Sexual and Reproductive Health service; VCT, Voluntary Counseling and Testing 


\section{Declarations}

\section{Ethics Approval}

The study was reviewed and approved by the Institutional Review Board (IRB) of Arba Minch University College of Medicine and Health Science. The study purpose, procedures, and benefits were explained to participants in local languages. Informed consent was obtained from participants and for participants who were under 18 years of age parental consent was obtained before they filled questionnaires. They were also assured that the information provided would be used only for research purpose and would therefore be strictly anonymous and dealt with confidentially.

Consent for Publication: Not applicable

Availability of Data Materials: Datasets used and/or analyzed during the current study are available from the corresponding author on reasonable request.

Competing Interests: The authors declare that they have no competing interests.

Funding: The study was funded by Arba Minch University, Ethiopia. The funder had no role in the study design, data collection, analysis, and interpretation of data.

\section{Authors' Contributions}

MM: drafted study design, carried out data collection supervision, data management, data analysis, and interpretation. GS: participated in statistical data analysis, result interpretation, and prepared the manuscript. MG: participated in data analysis and interpretation and revised the drafted manuscript. ZG: participated in the study design and revised the drafted manuscript. FW: participated in data analysis and interpretation and revised the drafted manuscript. GB: revised the drafted manuscript. All authors read and approved the final manuscript.

\section{Acknowledgment}

We would like to thank Arba Minch University for funding this research. We extend our thanks and sincere appreciation also go to supervisors, data Collectors and study participants for contribution to the success of the data collection.

\section{References}

1. WHO, Reproductive health. 2008.

2. Collumbien M, B.J., Cleland J, , Oona Campbell Social Science Methods for Research on Reproductive Health. Geneva. 2010.

3. WHO and Deutsche Gesellschaft fuer Technische Zusammenarbeit (GTZ) GmbH: Sexually transmitted infections among adolescents: the need for adequate health services. 2005. 
4. Haub, C., World population data sheet. PRB., 2013,.

5. SW., S., Adolescent Reproductive and Sexual Health, Facts for Policymakers. . 2010.

6. Ashiru, M., Women's health reproductive health marriage law legistilation women's rights children's rights female circumcision abortion. East ASfricaian Journal of pease and Human Rights., 2012.

7. Ramathuba , D., Sexuality reproductive health gender inequality communication .Indilinga. . 2012.

8. Health, F.D.R.o.E.M.o., Reproductive health at a glance in Ethiopia. 2011.

9. Bongaarts, J., et al., , Family planning programs for the 21 st century. New York: Population Council,. 2012.

10. Singh, S., J.E. Darroch, and L.S. Ashford, Adding it up: The costs and benefits of investing in sexual and reproductive health 2014. 2014.

11. UNFPA, status report on adolescents and young people in Sub-Saharan Africa. Opportunities and challenges African regional office Johannesburg South Africa. 2012.

12. United Nations Development of Economic and Social Association, Youth population trends and sustainable development. 2015.

13. United Nations Population Fund, Status Report on Adolescents and Young People In Sub-Saharan Africa; Opportunities and Challenges. . 2012.

14. Central Statistical Agency of Ethiopia, Ethiopia Mini Demographic and Health Survey. 2014.

15. EDHS, Central Statistical Agency [Ethiopia] and ICF International:Ethiopia Demographic and Health Survey 2016.

16. Gore FM, B.P., Patton GC, Ferguson J, Joseph V, Coffey C, Mathers CD. , Global burden of disease in young people aged 10-24 years:. 2011.

17. Ethiopia;, I., Building healthy future for Ethiopia's youth; Addis Ababa, Ethiopia. . 2014.

18. International:, C.S.A.E.a.I., Ethiopia Demographic and Health Survey 2011. Addis Ababa, Ethiopia and Calverton, Maryland, USA: Central Statistical Agency and ICF International. . 2012.

19. Ayalew.T, M.G.Y.Y., . Reproductive Health Knowledge and Attitude among Adolescents. A community based study in Jimma Town, Southwest Ethiopia. . 2008.

20. Feleke, S.e., Reproductive health service utilization and associated factors among adolescents (1519 years old) in Gondar town, Northwest Ethiopia. . 2013.

21. Motuma, A.e., Utilization of youth friendly services and associated factors among youth in Harar town, east Ethiopia: a mixed method study. BMC Health Services Research,, 2016.

22. Ayehu A, K.T., Hailu G.. , Level of Young People Sexual and Reproductive Health Service Utilization and Its Associated Factors among Young People in Awabel District, Northwest Ethiopia. . 2016.

23. Cherie, N., G. Tura, and N.T. Aderajew, , Reproductive health needs and service utilization among youths in West Badewacho Woreda, Hadiya Zone, South Ethiopia. . Journal of public health and epidemiology ,, 2015. 7(4):: p. p. 145-153.

24. Binu W, M.T., Gerbaba M and Sinaga M, , Sexual and reproductive health services utilization and associated factors among secondary school students in Nekemte town, Ethiopia. 2018. 
25. Teshale Tigistu Lejibo, S.A., Muktar Beshir, Tilahun Beyene Handiso.,, Reproductive Health Service Utilization and Associated Factors Among Female Adolescents in Kachabirra District, South Ethiopia. 2017.

26. Tejineh, S.e.a., Awareness, Utilization and Barriers to Family Planning Services among Female Students at Asella Preparatory School, Ethiopia. . Gynecology\& Obstetrics (Sunnyvale) an open access Journal,, 2015.

27. Abajobir AA, Seme A. Reproductive health knowledge and services utilization among rural adolescents in east Gojjam zone, Ethiopia: a community-based cross-sectional study. BMC health services research. 2014 Dec;14(1):1-1.

28. Gebreselassie B, T.A., Bililign N, Adera A, Yimam Y, Woreta A, Kidane M, , Assessment of Reproductive Health Service Utilization and Associated Factors Among Adolescents (15-19 Years Old) in Goba Town, Southeast Ethiopia. 2015.

29. Ebrahim, S.a.M., N., Knowledge, Attitude and Practice of family planning among women in Basrah city South of Iraq. . 2011.

30. Gupta M, B.N., Bahagana p., , Inequity in Awareness and Utilization of Adolescent Reproductive and Sexual Health Services in Union Territory, Chandigarh, . 2015.

31. Negash W, D.M., \& Yitayew B, Demsie M, Wagnew M, Nyagero J „Reproductive health service utilization and associated factors: the case of North Shewa zone youth, Amhara region, Ethiopia. . 2016.

32. Geleto. M, J.C., Tafese F, Reproductive Health Services Utilization and Associated Factors Among Adolescents in Anchar District, East Ethiopia. . 2017.

33. Sanga Z, K.G., Msuya S, Mwangi R., , Factors influencing the uptake of Voluntary HIV Counseling and Testing among secondary school students in Arusha City, Tanzania: cross sectional study BMC Public Health,, 2015.

34. Helamo, D., et al., Utilization and factors affecting adolescents and youth friendly reproductive health services among secondary school students in Hadiya Zone, Southern Nations, Nationalities and Peoples Region, Ethiopia. Int J Pub Heal Safe., 2017. 2(141): p. 2.

35. Ssebunya, R.N., et al., Prevalence and correlates of HIV testing among adolescents 10-19 years in a post-conflict pastoralist community of Karamoja region, Uganda. BMC public health, 2018. 18(1): $p$. 612.

36. Namazzi JA. Determinants of using voluntary counseling and testing for HIV/AIDS in Kenya. Journal of Management Policy and Practice. 2010 Dec 1;11(5):89-96.

\section{Tables}

Table 1: Socio demographic characteristics of study subjects preparatory school, in Arba Minch southern Ethiopia, Dec. 2019 G.C. 


\begin{tabular}{|c|c|c|c|}
\hline Variable & & frequency & Percent \\
\hline \multirow[t]{2}{*}{ Sex } & Male & 296 & 56.7 \\
\hline & Female & 226 & 43.3 \\
\hline \multirow[t]{2}{*}{ Age } & $15-16$ & 26 & 5 \\
\hline & $17-19$ & 496 & 95 \\
\hline \multirow[t]{2}{*}{ Educational status } & $11^{\text {th }}$ grade & 216 & 41.4 \\
\hline & $12^{\text {th }}$ grade & 306 & 58.6 \\
\hline \multirow[t]{3}{*}{ Marital status } & Single & 499 & 95.6 \\
\hline & Married & 21 & 4 \\
\hline & Divorced & 2 & 0.4 \\
\hline \multirow[t]{4}{*}{ Religion } & Orthodox & 252 & 48.2 \\
\hline & Protestant & 22 & 4.2 \\
\hline & Muslim & 247 & 47.3 \\
\hline & Others & 1 & 0.2 \\
\hline \multirow[t]{6}{*}{ Ethnicity } & Gamo & 380 & 72.8 \\
\hline & Gofa & 44 & 8.4 \\
\hline & Amara & 32 & 6.1 \\
\hline & Wolayta & 26 & 5 \\
\hline & Zeyise & 24 & 4.6 \\
\hline & Others & 16 & 3.1 \\
\hline \multirow[t]{6}{*}{ Co residence } & with both parents & 334 & 64 \\
\hline & With mother only & 66 & 12.6 \\
\hline & With father only & 21 & 4 \\
\hline & With relatives & 40 & 7.7 \\
\hline & With friends & 52 & 10 \\
\hline & Alone & 9 & 1.7 \\
\hline \multirow[t]{2}{*}{ Father's educational status } & No formal education & 48 & 9.2 \\
\hline & $\begin{array}{l}\text { Completed primary } \\
\text { education(1-8) }\end{array}$ & 187 & 35.8 \\
\hline
\end{tabular}




\begin{tabular}{|c|c|c|c|}
\hline & Completed secondary education & 127 & 24.3 \\
\hline & Above secondary education & 160 & 30.7 \\
\hline \multirow[t]{5}{*}{ Mother's educational status } & No formal education & 93 & 17.8 \\
\hline & Completed primary & 240 & 46 \\
\hline & education(1-8) & & \\
\hline & Completed secondary education & 117 & 22.4 \\
\hline & Above secondary education & 72 & 13.8 \\
\hline \multirow[t]{3}{*}{ Father's occupational status } & Formal employment & 188 & 36 \\
\hline & Casual laborer & 66 & 12.6 \\
\hline & Self-employment & 268 & 51.3 \\
\hline \multirow[t]{4}{*}{ Mother's occupational status } & Formal employment & 88 & 16.9 \\
\hline & Casual laborer & 18 & 3.4 \\
\hline & Self-employment & 70 & 13.4 \\
\hline & House wife & 346 & 66.3 \\
\hline
\end{tabular}

Table 2: Sexual history of the study participants in preparatory schools of Arba Minch town, Southern Ethiopia

\begin{tabular}{|llll|}
\hline Variables & Response & Frequency & Percent \\
\hline Ever had boy/girlfriend & Yes & 307 & 58.8 \\
\cline { 2 - 4 } & No & 215 & 41.2 \\
\hline Ever had sexual intercourse & Yes & 159 & 30.5 \\
\cline { 2 - 4 } & No & 363 & 69.5 \\
\hline Number of sexual partner & One & 166 & 54 \\
\cline { 2 - 4 } & Two and above & 141 & 46 \\
\cline { 2 - 4 } & &
\end{tabular}

Table 3: The frequency source of information for study participants Arba Minch, Southern Ethiopia, Dec. 2019 


\begin{tabular}{|llll|}
\hline Variables & Response & Frequency & Percent \\
\hline Parents & Yes & 69 & 13.2 \\
\cline { 2 - 4 } Friends & No & 453 & 86.8 \\
\hline Teachers & Yes & 72 & 13.8 \\
\cline { 2 - 4 } & No & 450 & 86.2 \\
\hline Mass media & Yes & 83 & 15.9 \\
\cline { 2 - 4 } & No & 369 & 84.1 \\
\hline Health worker & Yes & 122 & 23.4 \\
\cline { 2 - 4 } & No & 400 & 76.6 \\
\cline { 2 - 4 } & Yes & 122 & 23.4 \\
\hline
\end{tabular}

Table 4: Types of contraceptives ever utilized among preparatory school students, Arba Minch, Southern Ethiopia Dec. 2019 ( $n=522)$

\begin{tabular}{|c|c|c|c|}
\hline Variables & Response & Frequency & Percent \\
\hline \multirow[t]{2}{*}{ Male condom } & Yes & 330 & 63.2 \\
\hline & No & 192 & 36.8 \\
\hline \multirow[t]{2}{*}{ Female condom } & Yes & 17 & 3.2 \\
\hline & No & 505 & 96.8 \\
\hline \multirow[t]{2}{*}{ pills } & Yes & 188 & 36.0 \\
\hline & No & 334 & 64.0 \\
\hline \multirow[t]{2}{*}{ Injectable } & Yes & 54 & 10.4 \\
\hline & No & 468 & 89.6 \\
\hline \multirow[t]{2}{*}{ Implants } & Yes & 38 & 7.2 \\
\hline & No & 484 & 92.8 \\
\hline \multirow[t]{2}{*}{ Others } & Yes & 17 & 3.2 \\
\hline & No & 505 & 96.8 \\
\hline
\end{tabular}


Table 5: Reason for not utilizing VCT service among preparatory school students in Arba Minch town, Southern Ethiopia.

\begin{tabular}{|c|c|c|c|}
\hline Variables & & Frequency & Percent \\
\hline \multirow[t]{2}{*}{ I have no money } & Yes & 77 & 14.8 \\
\hline & No & 445 & 85.2 \\
\hline \multirow[t]{2}{*}{ Felt ashamed } & Yes & 171 & 32.8 \\
\hline & No & 351 & 67.2 \\
\hline \multirow[t]{2}{*}{ Clinic is closed } & Yes & 68 & 13.0 \\
\hline & No & 454 & 87.0 \\
\hline \multirow[t]{2}{*}{ Non covenant behavior of health workers } & Yes & 86 & 16.5 \\
\hline & No & 436 & 83.5 \\
\hline
\end{tabular}

Table 6: Bi-variable and multivariable logistic regression analysis of associated factors for F/P service utilization among preparatory school adolescents, in Arba Minch town, Southern Ethiopia, Dec. 2019 $(n=522)$ 


\begin{tabular}{|c|c|c|c|c|c|c|}
\hline \multirow[t]{2}{*}{ Variable } & & \multicolumn{2}{|c|}{$\begin{array}{l}\text { F/P service } \\
\text { utilization }\end{array}$} & \multirow{2}{*}{$\begin{array}{l}\operatorname{COR}(95 \% \\
\text { ci) }\end{array}$} & \multirow[t]{2}{*}{$\operatorname{AOR}(95 \%, \mathrm{ci})$} & \multirow[t]{2}{*}{$\begin{array}{l}\mathrm{p}- \\
\text { value }\end{array}$} \\
\hline & & Yes & No & & & \\
\hline \multirow[t]{2}{*}{ Sex } & Male & 61 & 235 & $\begin{array}{l}0.65(0.43- \\
0.94)\end{array}$ & $\begin{array}{l}1.18(0.646- \\
2.16)\end{array}$ & 0.587 \\
\hline & Female & 64 & 162 & 1 & 1 & \\
\hline \multirow[t]{2}{*}{ marital status } & Married & 23 & 6 & $\begin{array}{l}14.69(5.83- \\
37.04)\end{array}$ & $\begin{array}{l}3.96(1.08- \\
14.52)^{*}\end{array}$ & 0.037 \\
\hline & Unmarried & 102 & 391 & 1 & 1 & \\
\hline \multirow[t]{2}{*}{ co-residence } & $\begin{array}{l}\text { with both } \\
\text { parents }\end{array}$ & 68 & 266 & $\begin{array}{l}0.58(0.39- \\
0.88)\end{array}$ & $\begin{array}{l}0.76(0.41- \\
1.39)\end{array}$ & 0.376 \\
\hline & With others & 57 & 131 & 1 & 1 & \\
\hline \multirow[t]{2}{*}{ Mother educational status } & Educated & 111 & 318 & $\begin{array}{l}0.508(0.276- \\
0.933)\end{array}$ & $\begin{array}{l}0.573(0.248- \\
1.324)\end{array}$ & 0.192 \\
\hline & $\begin{array}{l}\text { No } \\
\text { education }\end{array}$ & 14 & 79 & 1 & 1 & \\
\hline \multirow[t]{3}{*}{ Father occupational status } & $\begin{array}{l}\text { Formal } \\
\text { employment }\end{array}$ & 74 & 194 & $\begin{array}{l}0.579(0.366- \\
0.915)\end{array}$ & $\begin{array}{l}0.734(0.372- \\
1.448)\end{array}$ & 0.372 \\
\hline & daily laborer & 17 & 49 & $\begin{array}{l}0.910(0.493- \\
1.679)\end{array}$ & $\begin{array}{l}0.473(0.193- \\
1.159)\end{array}$ & 0.102 \\
\hline & Self-employ & 34 & 154 & 1 & 1 & \\
\hline \multirow[t]{2}{*}{ discussed about RH } & Yes & 98 & 218 & $\begin{array}{l}2.98(1.86- \\
4.767)\end{array}$ & $\begin{array}{l}0.983(0.46- \\
2.09)\end{array}$ & 0.965 \\
\hline & No & 27 & 179 & 1 & 1 & \\
\hline \multirow[t]{2}{*}{ discussed about F/P } & Yes & 64 & 110 & $\begin{array}{l}2.73(1.81- \\
4.14)\end{array}$ & $\begin{array}{l}1.51(0.72- \\
3.09)\end{array}$ & 0.273 \\
\hline & No & 61 & 287 & 1 & 1 & \\
\hline \multirow[t]{2}{*}{$\begin{array}{l}\text { have you discussed on } \mathrm{RH} \\
\text { with parents }\end{array}$} & Yes & 44 & 50 & $\begin{array}{l}3.77(2.35- \\
6.04)\end{array}$ & $\begin{array}{l}2.76(1.25- \\
6.16)^{\star}\end{array}$ & 0.012 \\
\hline & No & 81 & 347 & 1 & 1 & \\
\hline \multirow[t]{2}{*}{$\begin{array}{l}\text { have you discussed on RH } \\
\text { with health workers }\end{array}$} & Yes & 13 & 18 & $\begin{array}{l}2.44(1.16- \\
5.14)\end{array}$ & $\begin{array}{l}2.15(0.66- \\
6.96)\end{array}$ & 0.201 \\
\hline & No & 112 & 379 & 1 & & \\
\hline \multirow[t]{2}{*}{$\begin{array}{l}\text { have you ever had sexual } \\
\text { intercourse }\end{array}$} & Yes & 108 & 51 & $\begin{array}{l}43.1(23.89- \\
77.74)\end{array}$ & $\begin{array}{l}8.24(6.1- \\
15.76)^{\star \star}\end{array}$ & 0.000 \\
\hline & No & 17 & 346 & 1 & 1 & \\
\hline
\end{tabular}


Key * =significantly associated, $* *=$ strongly associated $\& 1=$ reference

Table 7: Bi-variable and multivariable logistic regression analysis of determinant factors for VCT service utilization among preparatory schools, Arba Minch town, Southern Ethiopia Nov.2019 ( $n=522)$.

\begin{tabular}{|c|c|c|c|c|c|c|}
\hline \multirow[t]{2}{*}{ Variable } & & \multicolumn{2}{|c|}{$\begin{array}{l}\text { VCT } \\
\text { utilization }\end{array}$} & \multirow[t]{2}{*}{$\begin{array}{l}\text { COR( } 95 \% \text {, } \\
\text { ci) }\end{array}$} & \multirow[t]{2}{*}{$\operatorname{AOR}(95 \%, \mathrm{ci})$} & \multirow[t]{2}{*}{ p-value } \\
\hline & & Yes & No & & & \\
\hline \multirow[t]{2}{*}{ co-residence } & With all parents & 108 & 226 & $\begin{array}{l}1.51(1.01- \\
2.27)\end{array}$ & $\begin{array}{l}1.63(1.06- \\
2.49)^{\star}\end{array}$ & 0.024 \\
\hline & With others & 45 & 143 & 1 & 1 & \\
\hline \multirow[t]{2}{*}{$\begin{array}{l}\text { mother educational } \\
\text { status }\end{array}$} & $\begin{array}{l}\text { No formal } \\
\text { education }\end{array}$ & 17 & 76 & $\begin{array}{l}0.48(0.27- \\
0.84)\end{array}$ & $\begin{array}{l}0.53(0.29- \\
0.94)^{\star}\end{array}$ & 0.03 \\
\hline & Educated & 136 & 293 & 1 & 1 & \\
\hline \multirow[t]{2}{*}{ Discussed about RH } & Yes & 104 & 212 & $\begin{array}{l}1.57(1.05- \\
2.39)\end{array}$ & $\begin{array}{l}0.74(0.41- \\
1.34)\end{array}$ & 0.332 \\
\hline & No & 49 & 157 & 1 & 1 & \\
\hline \multirow[t]{2}{*}{$\begin{array}{l}\text { Discussed on RH with } \\
\text { friends }\end{array}$} & Yes & 71 & 126 & $\begin{array}{l}1.67(1.13- \\
2.45)\end{array}$ & $\begin{array}{l}1.38(1.83- \\
2.38)\end{array}$ & 0.242 \\
\hline & No & 82 & 243 & 1 & 1 & \\
\hline \multirow[t]{2}{*}{$\begin{array}{l}\text { Discussed on } \mathrm{RH} \text { with } \mathrm{H} / \\
\text { workers }\end{array}$} & Yes & 15 & 16 & $\begin{array}{l}2.39(1.15- \\
4.98)\end{array}$ & $\begin{array}{l}2.53(1.14- \\
5.61)^{\star}\end{array}$ & 0.032 \\
\hline & No & 138 & 353 & & 1 & \\
\hline \multirow[t]{2}{*}{ Discussed about VCT } & Yes & 77 & 118 & $\begin{array}{l}2.15(1.46- \\
4.01)\end{array}$ & $\begin{array}{l}2.07(1.21- \\
3.57)^{\star}\end{array}$ & 0.008 \\
\hline & No & 76 & 251 & 1 & 1 & \\
\hline
\end{tabular}

Key $*=$ significantly associated, ${ }^{* *}=$ strongly associated $\& 1=$ reference

\section{Figures}




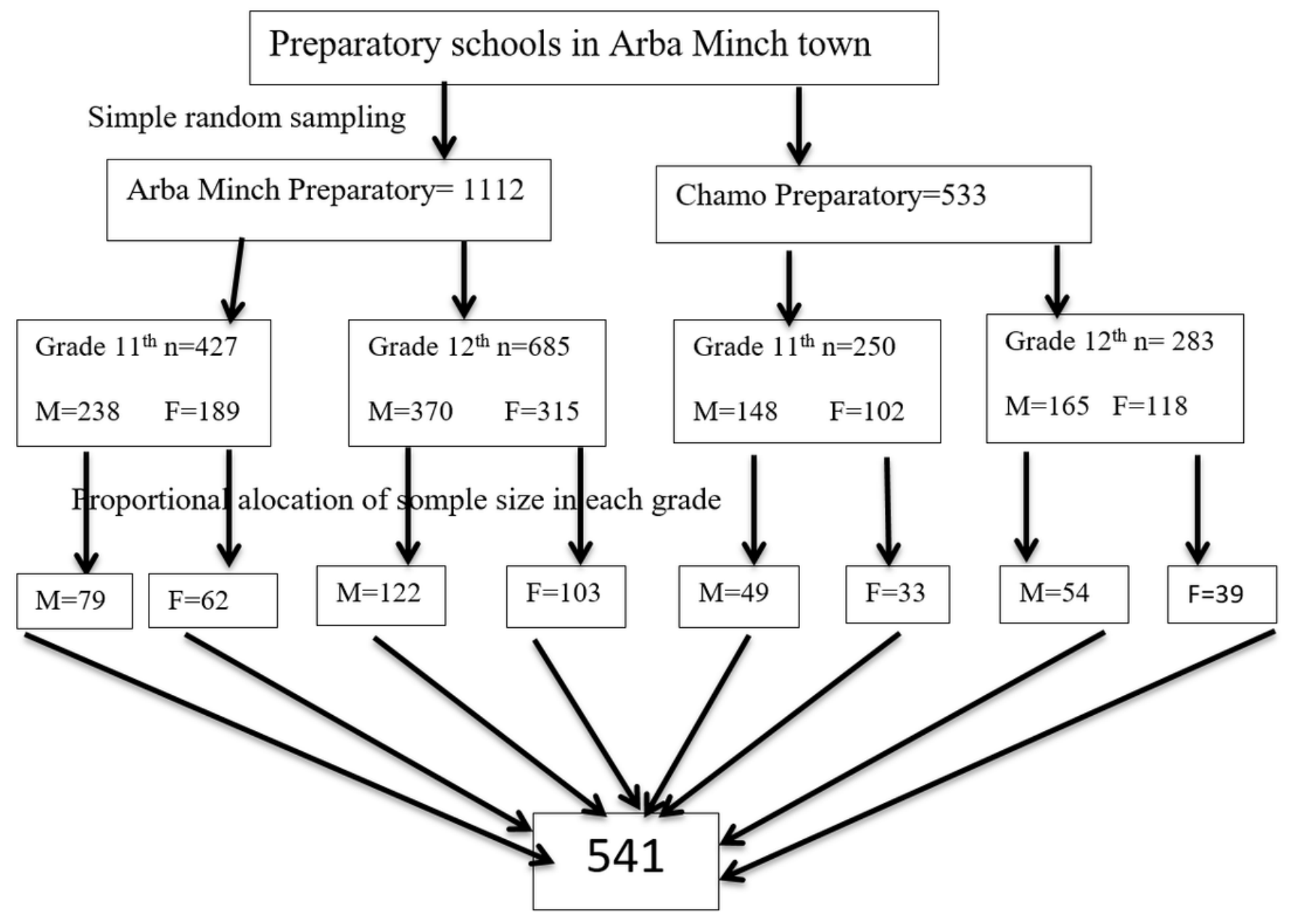

Figure 1

Diagrammatic presentation of sampling procedure 